\title{
Effect of Waste Oil-Cracking Catalyst Incorporation on Durability of Mortars
}

\author{
Carla Costa ${ }^{*}$, M. Sofia Ribeiro² ${ }^{2}$ Nuno Brito ${ }^{1}$ \\ ${ }^{1}$ Department of Civil Engineering, High Institute of Engineering of Lisbon (ISEL), Lisbon, Portugal \\ ${ }^{2}$ Materials Department, National Laboratory for Civil Engineering (LNEC), Lisbon, Portugal \\ Email: ${ }^{*}$ carlacosta@dec.isel.pt
}

Received 15 August 2014; revised 19 September 2014; accepted 2 October 2014

Copyright (C) 2014 by authors and Scientific Research Publishing Inc.

This work is licensed under the Creative Commons Attribution International License (CC BY). http://creativecommons.org/licenses/by/4.0/

CC) (7) Open Access

\begin{abstract}
This paper presents research on transport properties and alkali-silica reaction (ASR) susceptibility of mortars containing a pozzolanic waste generated in the fluid catalytic cracking (wFCC) unit by the Portuguese oil-refinery. For this purpose, two series of mortars were prepared by partially replacing cement with $5 \%, 10 \%$ and $15 \%$ of wFCC catalyst. The main difference between the two series of mortars is the sand reactivity used in their composition. The results revealed that wFCC catalyst blended cement mortars exhibit an increased resistance against capillary water absorption and chloride migration, as well as a considerable inhibition effect on deleterious ASR expansion. However, under the adopted experimental conditions the incorporation of wFCC catalyst in mortars decreases their carbonation resistance.
\end{abstract}

\section{Keywords}

Waste Oil-Cracking Catalyst, Blended Cement Mortars, Water Absorption, Chloride Migration, Resistance to Carbonation, Alkali-Silica Reaction, Durability

\section{Introduction}

It is generally accepted that the incorporation of pozzolanic materials (PMs) in cement based materials plays a crucial role towards sustainable development of the construction industry by addressing environmental and performance issues in an integrated way. In fact, partial replacement of cement with PMs reduces the use of nonrenewable raw materials and energy as well as decreases the $\mathrm{CO}_{2}$ footprint in cement plants [1]-[3]. In addition, if the surrogate material is a waste from other industry it would also contribute to mitigate solid waste disposal of in landfills and to turn a polluting waste from one industry into a product with added-value for cement industry [4]. Furthermore, PMs, typically, lead to performance and durability enhancement due to the formation of

*Corresponding author. 
additionally strength-providing hydrated calcium aluminosilicates (C-A-S-H) products during PMs reaction with the $\mathrm{Ca}(\mathrm{OH})_{2}$ (liberated upon cement hydration) [5].

By-products such as silica fumes, fly ashes and ground blast-furnace slags have been extensively used in past decades to replace part of the cement as PMs for different uses in construction industry [3] [6]. However, the uncertainty about future availability of commonly used PMs concomitantly with the aforementioned environmental and technological reasons are highlighting the need of identifying additional PMs able to comply with construction materials standards, performance targets as well as market needs. In this scope, the waste catalyst originated in the fluid catalytic cracking (wFCC) units by oil-refinery companies [7]-[20] is being investigated. This study focuses on this purpose.

Currently, oil-refineries worldwide generate around 500,000 metric tons/year of waste catalyst in their fluid catalytic cracking units [21] and, therefore, it is available in significant amounts. FCC catalysts are typically "taylor-made" for each oil-refinery based on the feed composition and desired products spectra [22]. Despite not being a commodity, the chemical-mineralogical and physical properties-namely the particle size distribution - of a given wFCC catalyst generated in the same oil-refinery remain almost constant for some years. As such, this by-product can be a steady supply for the construction materials industry.

The FCC catalyst is an aluminosilicate which most active phase is zeolite-Y [23]. The high pozzolanic reactivity of this by-product has been confirmed by various methods. Namely, its ability to react directly with lime has been demonstrated through classic titrimetric methods including the Frattini-based test [12] and the Chapelle test [11]. Whereas its ability to react with the $\mathrm{Ca}(\mathrm{OH})_{2}$ present in cement matrices as well as the consequent formation of the C-A-S-H products, have been assessed by means of thermo-gravimetric analysis (TGA) [9] [17] [19], X-ray diffraction (XRD) [18] and scanning electron microscopy (SEM) [16].

Several studies have shown that the replacement of cement with wFCC catalysts up to $15 \%-20 \%$, by mass, in mortars and concrete enhances both their early and long term compressive strength [8] [10] [15] [18] [24]-[26]. It has also been shown that the strength of the cement-based materials is markedly enhanced for smaller grain sized catalysts [11] [14]. In terms of durability, it has also been shown that cement replacement with up to $10 \%$ of wFCC catalysts there is no additional contribution for the degradation of the cement based materials [7] [13] [20].

Despite of studies and above-mentioned benefits of the wFCC catalysts, to the best of the author's knowledge, the wastes are not yet being used by construction materials industry as PMs. The present study is part of a research project which main goal is to contribute to a better understanding of the pozzolanic reaction mechanism leading to the development of cement-based materials incorporating wFCC catalyst generated by the Portuguese oil-company such that large-scale industrial application can be archived in the future.

In this regards, the high pozzolanic reactivity of the Portuguese wFCC catalyst has already been confirmed by different methods [15] [16] [24] as well as several different applications had been tested with success both in terms of properties and compliance with the corresponding standards specifications. Namely, the results already demonstrated that this wFCC catalyst can be used as cement main constituent for common cements manufacture [15], as an addition for mortars [16] and concretes (both traditional and self-compacting) [25] [26] as well as in production of alkali-activated binders [27].

In spite of good structural performance while interacting with the service environment, wFCC catalyst containing cement-based materials can undergo deleterious reactions that can have adverse consequences both on properties and in-service lifetime. Therefore, to complement our previous studies, this paper describes research on the effect of the Portuguese wFCC catalyst on mortar's durability characteristics.

Since the majority of the deterioration processes involve the transport of the deleterious gases, liquids or ions through the porous of the cement pastes matrices, testing transport processes-such as absorption, migration and diffusion-it is crucial on the basis of durability assessment [28]. Moreover, alkali-silica reaction (ASR) has also been considered one of the biggest concerns in the design of durable cement-based materials [29]. As such, mortars prepared with Portuguese wFCC catalyst as partial cement replacer (5\% to $15 \%$, by mass) were tested for capillary water absorption behaviour, chloride migration and resistance to carbonation as well as ASR susceptibility.

\section{Experimental Program}

\subsection{Materials}

The binders used in this study were: commercial Portuguese Portland cement type CEM I 42.5R, according to 
European standard EN 197-1 and wFCC catalyst, generated by Portuguese refinery company PETROGAL S.A. at Sines. Table 1 lists bulk chemical composition of cement and wFCC catalyst, obtained by X-ray fluorescence spectrometry (using a PAN alytical model Axios equipment) and loss on ignition (LOI) evaluated following European standards EN 196-2. The specific gravities of cement and of wFCC catalyst of 3.18 and 2.71, respectively, were determined by helium pycnometry using an AccuPyc 1330 instrument from Micromeritics. The specific surface area of the wFCC particles of $150000 \mathrm{~m}^{2} / \mathrm{kg}$ was determined by nitrogen adsorption at $77 \mathrm{~K}$ using a Micromeritics ASAP 2000 apparatus.

The particle size distributions (PSD) of the cement and wFCC catalyst were obtained by laser diffraction. The $d_{50}$ and $d_{90}$ are, respectively, the values of particles sizes below which $50 \%$ and $90 \%$ (by volume) are situated. The $\mathrm{d}_{50}$ of cement and wFCC particles are $21.5 \mu \mathrm{m}$ and $80.0 \mu \mathrm{m}$, respectively and the $\mathrm{d}_{90}$ of cement and wFCC particles are $56.0 \mu \mathrm{m}$ and $124.3 \mu \mathrm{m}$, respectively.

Two different sands were used: one unreactive sand (ur-s) and one reactive sand (r-s). The ur-s was a natural siliceous sand normalized according to EN 196-1 standard (manufacturer: Société Nouvelle du Littoral, France). The r-s was prepared from a pebblestone aggregate provided with minimum (d) and maximum (D) particle dimensions of, respectively, $5.6 \mathrm{~mm}$ and $11.2 \mathrm{~mm}$. This aggregate was crushed to obtain the grading specified in the ASTM C 1260 standard for alkali reactivity test. After crushing and combining the different grades in the required proportions, the properties of the resulting aggregate were determined according to EN 933-1 standard (minimum particle dimension of $0.125 \mathrm{~mm}$; maximum particle dimension of $4 \mathrm{~mm}$; fineness modulus of 3.99). In addition, an ASTM C 1260 test was conducted to assess its alkali reactivity. The alkali reactivity of the pebblestone was confirmed, as the expansion at 14 days was of $0.22 \%$ and, thus, higher than the $0.20 \%$ lower limit for reactive aggregates specified in ASTM C 1260. Superplasticizer (SP) SikaPlast 898 and deionized water were used in mortars preparation.

\subsection{Mortar Mixtures Proportions}

The experimental program included the preparation of two different series of mortar mixtures in which cement was partially replaced with wFCC catalyst within the range of $5 \%$ to $15 \%$ (by mass) with an increment of $5 \%$. Plain cement mortars were also prepared as reference mortars. The main difference between the two series of mortars consisted in the sand used in their preparation: one of the mortars series used the ur-s, whereas the other series used the r-s in order to perform the ASR test.

Table 2 describes the mixtures proportions used in the mortars and discriminates the tests carried out with each series of mortars.

Table 1. Bulk chemical composition of the cement and wFCC catalyst (\%, by mass).

\begin{tabular}{llllllllllllll} 
Binder & $\mathrm{SiO}_{2}$ & $\mathrm{Al}_{2} \mathrm{O}_{3}$ & $\mathrm{Fe}_{2} \mathrm{O}_{3}$ & $\mathrm{CaO}$ & $\mathrm{MgO}$ & $\mathrm{SO}_{3}$ & $\mathrm{~K}_{2} \mathrm{O}$ & $\mathrm{Na}_{2} \mathrm{O}$ & $\mathrm{Ti}_{2} \mathrm{O}_{3}$ & $\mathrm{P}_{2} \mathrm{O}_{5}$ & $\mathrm{Mn}_{2} \mathrm{O}$ & $\mathrm{SrO}$ & $\mathrm{LOI}^{*}$ \\
\hline Cement & 19.41 & 5.45 & 3.23 & 62.57 & 1.91 & 2.89 & 1.10 & 0.00 & 0.27 & 0.10 & 0.05 & 0.07 & 2.70 \\
wFCC & 39.59 & 52.81 & 0.55 & 0.09 & 0.19 & 0.23 & 0.04 & 0.68 & 0.82 & 0.06 & 0.00 & 0.00 & 1.49 \\
\hline
\end{tabular}

*LOI-Loss on ignition.

Table 2. Mortars mixtures proportions and discrimination of performed tests.

\begin{tabular}{|c|c|c|c|c|c|}
\hline \multirow{2}{*}{$\begin{array}{c}\text { Series of } \\
\text { mortars }\end{array}$} & \multirow{2}{*}{ Notation } & \multirow{2}{*}{$\begin{array}{l}\text { Mixture } \\
\text { proportions }\end{array}$} & \multicolumn{2}{|c|}{ Binder (\% by mass) } & \multirow{2}{*}{ Tests } \\
\hline & & & Cement & wFCC & \\
\hline \multirow{4}{*}{ Unreactive sand (ur-s) } & C100 & & 100 & 0 & \multirow{4}{*}{$\begin{array}{ll}\text { - } & \text { capillary water absorption } \\
\text { - } & \text { chloride migration } \\
& \text { accelerated carbonation }\end{array}$} \\
\hline & C95_wFCC5 & $05 / 2 / 1 / 0005$ & 95 & 5 & \\
\hline & C90_wFCC10 & $0.5 / 3 / 1 / 0.005$ & 90 & 10 & \\
\hline & C85_wFCC15 & & 85 & 15 & \\
\hline \multirow{4}{*}{ Reactive sand (r-s) } & ASR_C100 & $0.47 / 2.19 / 1$ & 100 & 0 & \multirow{4}{*}{ - $\quad$ alkali-silica reaction } \\
\hline & ASR_C95_wFCC5 & $0.49 / 2.19 / 1$ & 95 & 5 & \\
\hline & ASR_C90_wFCC10 & $0.49 / 2.19 / 1$ & 90 & 10 & \\
\hline & ASR_C85_wFCC15 & $0.51 / 2.19 / 1$ & 85 & 15 & \\
\hline
\end{tabular}

${ }^{1}$ Mixture proportions: for ur-s series of mortars corresponds to the w/ur-s/b/SP ratio (mass ratio of water (w) to unreactive sand (ur-s) to binder (b) and to superplasticizer (SP)); and for r-s series of mortars corresponds to the w/r-s/b ratio: mass ratio of water (w) to reactive sand (r-s) to binder (b)). 


\subsection{Methods}

The capillary water absorption, chloride migration and resistance to accelerated carbonation tests were carried out on us-r series of mortars and the alkali-silica reaction test was carried out on s-r series of mortars (Table 2). The mortars were mixed according to the procedure described in the EN196-1 standard with an exception for the previous mixture of the superplasticizer with water for us-r series of mortars.

The resistance to water absorption by capillary action was evaluated following the testing procedure described in the EN 13057 standard. The procedure consisted in preparing three replicates of cylindrical specimens $(\varnothing 100$ $\times 25 \mathrm{~mm}$ ) for each mortar mixture which were water cured for a period of 28 days. Thereafter, the specimens were dried in an oven at $40^{\circ} \mathrm{C}$ until reached a constant mass (defined as a weight change smaller than $0.2 \%$ in 2 hours). The measurements of water capillary absorption were carried out exposing one of the cylindrical faces of each specimen to water. During the experiment, the depth of immersion of tested specimens face is $2 \mathrm{~mm}$. The water ingress was calculated by measuring the increase in the mass of a specimen at various testing periods, namely, after $12 \mathrm{~min}, 30 \mathrm{~min}, 1$ hour, 2 hours, 4 hours and 24 hours from its first contact with water. The amount of water absorbed $(\mathrm{kg})$ was normalized with respect to the cross sectional area of the specimens exposed to water $\left(\mathrm{m}^{2}\right)$.

The resistance to chloride penetration was evaluated following the testing procedure described in the NT BUILD 492 standard. The procedure consists in preparing three replicates of cylindrical specimens $(\varnothing 100 \times 50$ $\mathrm{mm}$ ) for each mortar mixture which were water cured for a period of 28 days. The test steps were as follows: (i) the specimens were vacuum soaked with a $\mathrm{Ca}(\mathrm{OH})_{2}$-saturated solution; and (ii) application of a $10 \mathrm{~V}$ electrical potential that forces chloride ions from a $10 \% \mathrm{NaCl}$ solution (catholyte) to migrate in to the specimens. After 24 hours, each specimen was axially split into two pieces and the freshly split surfaces were sprayed with $0.1 \mathrm{M}$ silver nitrate solution. After 20 minutes, the chloride migration depth as well as the thickness of each specimen were measured.

The resistance to carbonation was evaluated through an accelerated carbonation test following the testing procedure described in the EN 13295 standard. The procedure consisted in preparing three replicates of prismatic specimens $(40 \times 40 \times 160 \mathrm{~mm})$, for each mortar mixture, which were water cured for a period of 28 days followed by their cure in a chamber (Aralab Fitoclima S600) at a temperature of $21^{\circ} \mathrm{C}$ and at a relative humidity of $60 \%$ for a period of 14 days. Thereafter, the specimens were kept inside the chamber exposed to an accelerated carbonation environment of $5 \% \mathrm{CO}_{2}$. After $0,18,28,56,74$ and 91 days of exposure to $\mathrm{CO}_{2}$, a slice of $15-20$ $\mathrm{mm}$ thickness was broken off from each prism and the freshly broken surfaces were sprayed with $1 \%$ solution of phenolphthalein. After 60 minutes of spraying the carbonation depth $\left(d_{\mathrm{K}}\right)$ was measured (in accordance with EN 14630 standard).

The evaluation of the effect of wFCC catalyst on potential ASR was carried out on r-s series of mortars in accordance with ASTM C1260-94 standard. Namely, this standard was followed for the test mortars proportioning as well as for mixing and molding procedure of the test specimens (three replicates of $25 \times 25 \times 285 \mathrm{~mm}$ prisms for each mortar mixture). The only exception to the described procedure consisted in the water to binder (w/b) ratio. In fact, although the standard specifies the use of a fixed water w/b ratio of 0.47 , due to the high water absorption ability of the wFCC catalyst particles [15], it was adopted a constant flow value for all tested mortars. As such, the flow value of the ASR_C100 mortar prepared with w/b ratio of 0.47 was assumed as the reference value and the $\mathrm{w} / \mathrm{b}$ ratios for the other mortars mixtures was adjusted in order to obtain the same flow. The actual mixture proportioning of the mortars is included in Table 1.

Thereafter, the specimens were: (i) initially, cured in a moist cabinet (temperature $20^{\circ} \mathrm{C}$ e RH70\%) for $24 \mathrm{~h}$; (ii) unmolded, and (iii) cured immersed in water at $80^{\circ} \mathrm{C}$ during $24 \mathrm{~h}$. The length of the specimens was monitored at this point for reference ("zero reading"). Subsequently, specimens were immersed in a $1 \mathrm{~N} \mathrm{NaOH}$ solution at $80^{\circ} \mathrm{C}$ for a period of 28 days during which expansion was monitored.

\section{Results and Discussion}

\subsection{Capillary Water Absorption}

Figure 1 plots the water intake by capillary action on us-r series of mortars against the square root of the time of immersion. The slope of the linear fit of these experimental results, for each mortar composition, provides the capillary absorption coefficient, $\mathrm{S}\left(\mathrm{kg} / \mathrm{m}^{2} \cdot \mathrm{h}^{0.5}\right)$, presented in Table 3. 


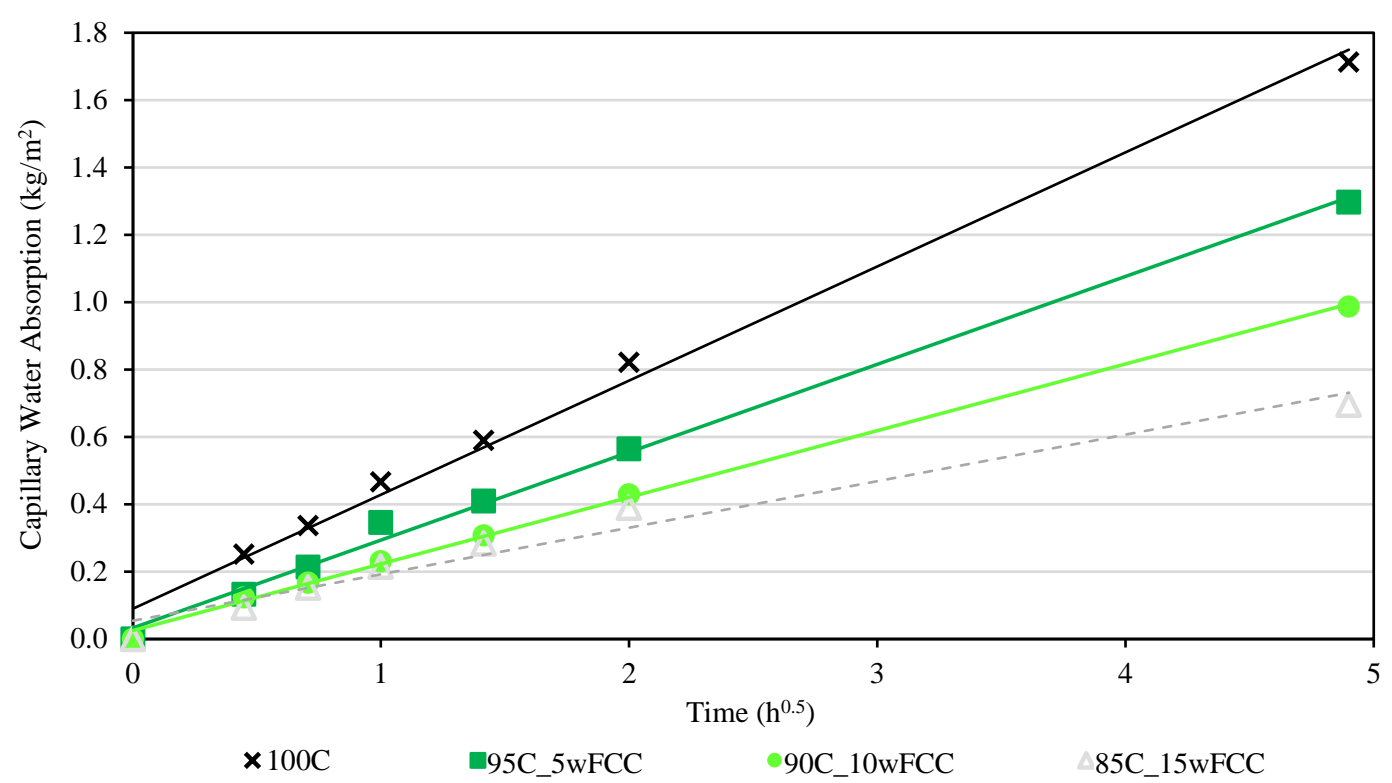

Figure 1. Water absorption by capillary action of mortars with $0 \%$ to $15 \%$ of cement replacement with wFCC catalyst.

Table 3. Capillary absorption coefficient, $\mathrm{S}\left(\mathrm{kg} / \mathrm{m}^{2} \cdot \mathrm{h}^{0.5}\right)$ of mortars with $0 \%$ to $15 \%$ of cement replacement with wFCC catalyst.

\begin{tabular}{cccc}
\hline C100 & C95_wFCC5 & C90_wFCC10 & C85_wFCC15 \\
\hline 0.34 & 0.26 & 0.20 & 0.14 \\
\hline
\end{tabular}

Capillary water absorption provides an indirect measure of the capillary pore volume and connectivity. Results presented in Figure 1 show that all the mortars incorporating wFCC catalyst exhibited lower water absorption than that of the reference plain cement mortar, C100. Moreover, increasing the wFCC content in the mortars composition leads to a linear reduction in values of the capillary water absorption coefficients (Table 3) which indicates a progressive increase in resistance to water absorption.

This revelation of lower capillary water absorption in cement based materials incorporating pozzolans is attributed to the formation of the pozzolanic reaction products C-A-S-H which lead both to the capillary pore-size refinement and to the decrease in their interconnectivity [6]. The results are in good agreement with previous studies using waste oil-cracking catalysts generated by other oil refineries [7] [20].

\subsection{Chloride Migration}

Table 4 presents chloride penetration depths, $x_{\mathrm{d}}$, obtained for us-r series of mortars as well as the non-steady state chloride migration coefficients, $D_{\text {nssm }}$, computed using Equation (1), as described in NT BUILD 492.

$$
D_{\text {nssm }}=\frac{0.0239(273+T) L}{(U-2) t} \times\left(x_{\mathrm{d}}-0.0238 \sqrt{\frac{(273+T) L x_{\mathrm{d}}}{U-2}}\right)
$$

where: $D_{\text {nssm }}$ is the non-steady state migration coefficient $\left(\times 10^{-12} \mathrm{~m}^{2} / \mathrm{s}\right)$; $U$ is the absolute value of the applied voltage $(\mathrm{V})$, in this case $10 \mathrm{~V} ; T$ is the average value of the initial and final temperatures in the anolyte solution $\left({ }^{\circ} \mathrm{C}\right) ; L$ is the measured values of specimen thickness $(\mathrm{mm}) ; x_{\mathrm{d}}$ is the average value of the penetration depths $(\mathrm{mm}) ; t$ is the test duration (h), in this case $24 \mathrm{~h}$.

The results included in Table 4 show that wFCC catalyst containing mortars have lower chloride penetration depths and smaller migration coefficients compared to those of the reference mortar, C100, i.e. incorporation of waste catalyst increases the chloride penetration resistance.

In addition, similarly to what was observed with the values of the capillary water absorption coefficients, in- 
creasing the wFCC content in the mortars composition leads to a linear reduction in $D_{\text {nssm }}$ values. However, the chloride migration is less affected by the densification of the blended cement pastes matrices promoted by the pozzolanic reaction products than the water absorption by capillarity. In fact, the $D_{\text {nssm }}$ ratios between plain cement mortar and the blended cement mortars with $5 \%, 10 \%$ and $15 \%$ of wFCC catalyst are, respectively, 1.08, 1.13 and 1.30 whereas the correspondent ratios for the capillary absorption coefficients are, respectively, 1.31 , 1.70 and 2.43 .

The increment on the chloride resistance penetration promoted by the waste catalysts generated in other oil refineries have already been reported elsewhere [13] [20].

\subsection{Resistance to Carbonation}

The carbonation depths of the mortars of the us-r series of mortars after different time of exposure to an accelerated carbonation environment of $5 \% \mathrm{CO}_{2}$ are represented in Figure 2.

Carbonation is a complex process that depends on several factors: environmental conditions such as $\mathrm{CO}_{2}$ concentration and humidity and on material characteristics like water to cement $(\mathrm{w} / \mathrm{c})$ ratio and type of cement. Most of the prediction models of the carbonation process in cement based materials are based on Fick's law for diffusion as shown in Equation (2).

$$
x_{\mathrm{C}}=k \sqrt{t}
$$

where: $x_{\mathrm{C}}$ is the carbonation deep (mm), $k$ is the carbonation coefficient and $t$ is the exposure time (days) to the $\mathrm{CO}_{2}$ environment.

However, the carbonation is not a steady state process, because as $\mathrm{CO}_{2}$ penetrates it can react with the cement hydration products such as $\mathrm{Ca}(\mathrm{OH})_{2}$ and the hydrated calcium silicates (C-S-H), changing the microstructure of the hardened cement paste. Therefore, the pore structure - size and connectivity —and the available carbonatable compounds changes with time and, hence, the carbonation coefficient, $k$, is also a time dependent parameter.

Table 4. Chloride penetration depths, $x_{\mathrm{d}}$, and non-steady state chloride migration coefficients, $D_{\text {nssm }}$, of mortars with $0 \%$ to $15 \%$ of cement replacement with wFCC catalyst.

\begin{tabular}{ccccc}
\hline & C100 & C95_wFCC5 & C90_wFCC10 & C85_wFCC15 \\
\hline$x_{\mathrm{d}}(\mathrm{mm})$ & 8.9 & 8.3 & 8.1 & 7.7 \\
$D_{\text {nssm }}\left(\times 10^{-12} \mathrm{~m}^{2} / \mathrm{s}\right)$ & 10.6 & 9.8 & 9.4 & 8.2 \\
\hline
\end{tabular}

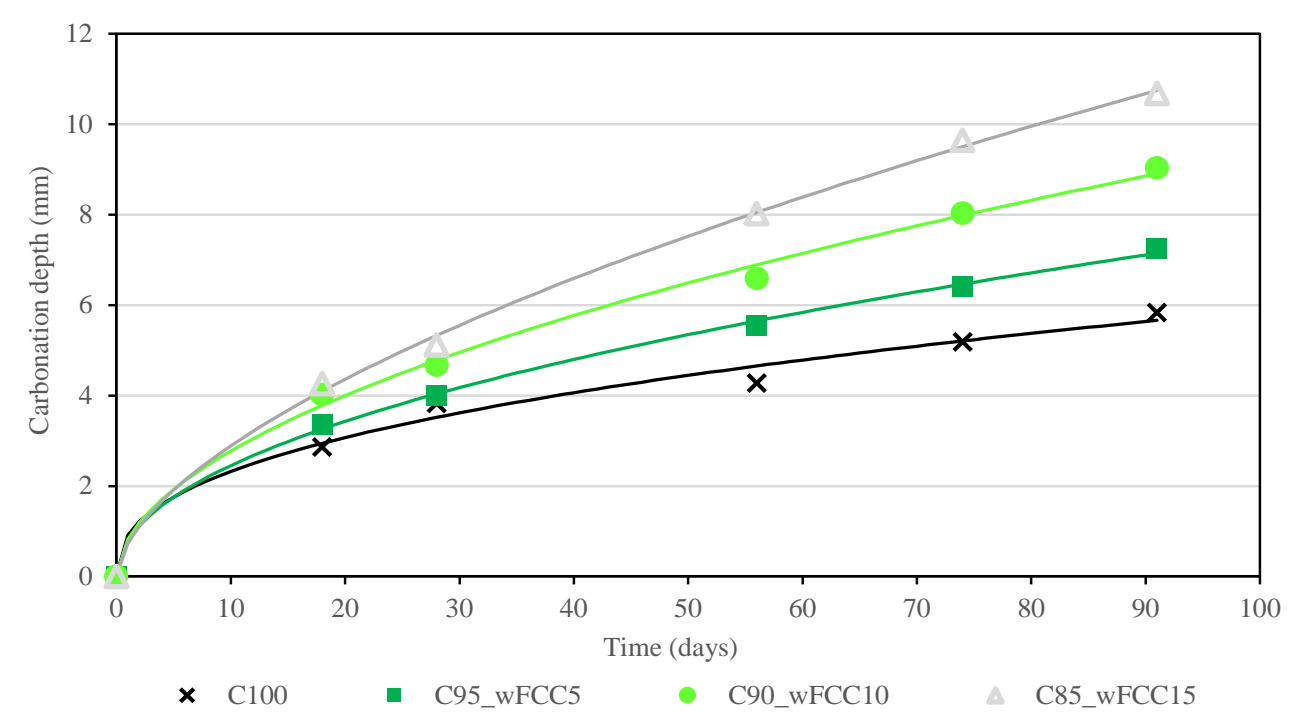

Figure 2. Carbonation depths on us-r series of mortars at different $\mathrm{CO}_{2}$ exposure time (symbols: correspond to experimental measured values; lines: correspond to fitting curves obtained from Equation (3) using the fitting parameters listed in Table 5). 
In order to accommodate the aforementioned additional complexity in the model and still keeping carbonation coefficient as a time-independent parameter, the carbonation rate can be expressed by a power-law relationship with time, $t^{n}$ (Equation (3)) in which the exponent, $n$, is an adjustable parameter that is able to be different of 0.5 (corresponding to the square root of time-diffusion of Equation (2)). This consists in a simple semi-empirical approach to improve the predictions in carbonation deep owing to the larger number of degrees of freedom of Equation (3) compared with that of Equation (2) [30] [31].

$$
x_{\mathrm{C}}=k t^{n}
$$

The carbonation rate parameters estimated by fitting the carbonation depth experimental data to the Equation (3) using the least-squares method are listed in the Table 5 and the corresponding fitting curves are represented in the Figure 2.

The results included in Figure 2 reveal that the wFCC cement blended mortars are more susceptible to carbonation than plain cement mortar, C100. These results are in agreement with typical results obtained in mortars with cement partially replaced with pozzolans [32] namely, with wFCC catalyst generated by other oil refineries [20] [33]. The presence of the pozzolans resulting in faster carbonation indicate that the reduction of the content of $\mathrm{Ca}(\mathrm{OH})_{2}$ in the cement paste matrix (consumed in the pozzolanic reaction) is not compensated by the denser structure produced by the additional pozzolanic reaction products, C-A-S-H. The increase of curing period or the decrease of w/c ratio [33] can approach the pozzolanic blended cement mortars behavior to that of the plain cement mortars.

Equation (3) considering the estimation of both kinetics parameters-carbonation coefficient and exponent of the time dependence-revealed to be a good-fitting model to express the carbonation rate since the fitted curves are in very good agreement with the corresponding experimental data (Figure 2). Results included in Table 5 show that the empirical exponent values, $n$, of the time dependence value may be either higher or lower than the usually adopted value of 0.5 (Equation (2)). Furthermore, the value of $n$ steadily increases with the wFCC catalyst incorporation in the binder whereas the carbonation coefficient, $k$, tends to decrease. In addition, the estimated $n$ values lie within the range of 0.4 to 0.6 in accordance with the values obtained in studies carried out on fly-ashes blended cement concretes [30] [31].

\subsection{Alkali-Silica Reaction}

The expansion results of the alkali-silica reactivity testing carried out in the r-s series of mortars are represented in Figure 3.

These results show that the presence of wFCC catalyst in the blended mortars leads to a reduction in the ASR expansion when compared with that of $\mathrm{C} 100$, the reference mortar. In fact, the average value of expansion of the reference specimen (C100) after 14 days of exposure to the alkali solution was $0.284 \%$ and after 28 days of exposure was $0.435 \%$. For mortars with 5\%, $10 \%$ and $15 \%$ of wFCC incorporation, the expansion values after 14 days of exposure to the alkali solution were, respectively, $0.204 \%, 0.165 \%$ and $0.153 \%$ and the expansion after 28 days were, respectively, $0.328 \%, 0.259 \%$, and $0.233 \%$. Therefore, the results show that the presence of the waste catalyst in the binder significantly contribute for the mitigation of ASR expansion of around $25 \%$ for the ASR_wFCC5, 40\% for the ASR_wFCC10 and 46\% for the ASR_wFCC15.

The effect of the wFCC catalyst presence in controlling the ASR occurrence was expected because the most active phase of the wFCC catalysts is the Y-zeolite which is an aluminosilicate with a crystalline structure consisting of a tri-dimensional network of tunnels and cages with a very specific surface area (SSA). In the case of the waste catalyst under study the SSA is of $150000 \mathrm{~m}^{2} / \mathrm{kg}$ (Section 2.1). This property, in addition with the high cation adsorption capacity of the Y-zeolite [34] [35] make the wFCC catalyst a good adsorbent for trapping

Table 5. Carbonation rate parameters of us-r series of mortars estimated by fitting the carbonation depth experimental data to the Equation (3) using the least-squares method.

\begin{tabular}{ccccc} 
& C100 & C95_wFCC5 & C90_wFCC10 & C85_wFCC15 \\
\hline$k\left(\mathrm{~mm} / \mathrm{d}^{\mathrm{n}}\right)$ & 0.92 & 0.80 & 0.82 & 0.73 \\
$n$ & 0.40 & 0.48 & 0.53 & 0.60 \\
\hline
\end{tabular}




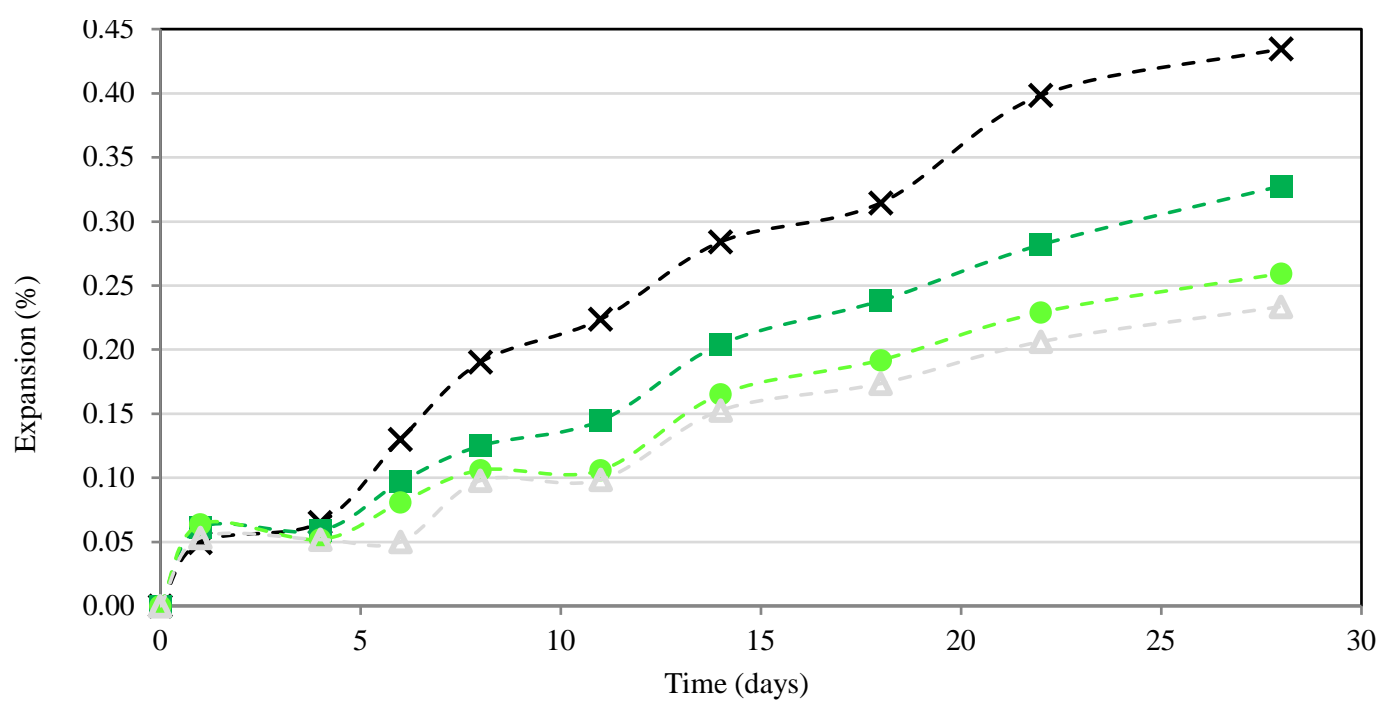

- - $\boldsymbol{*}$ - ASR C100 - - 프 - ASR C95 wFCC5

ASR_C90_wFCC10

ASR_C85_wFCC15

Figure 3. Expansion due to ASR on s-r series of mortars after different time of immersion in $1 \mathrm{~N} \mathrm{NaOH}$ solution.

alkalis. Therefore, the wFCC catalyst incorporated in cement matrices adsorbs part of the alkalis present and, as consequence, mitigates the deleterious expansion due to the ASR.

Moreover, the aforementioned increasing resistance to water penetration promoted by the wFCC catalyst (Section 3.1) also concurs for the reduction of ASR occurrence since the presence of water is an essential condition to favour this reaction.

In addition to zeolite-based materials [36], the partial cement replacement with pozzolanic materials is, typically, one of the most effective methods in controlling ASR [36]-[38].

\section{Conclusions}

This study examines durability parameters of mortars with up to $15 \%$, by mass, of cement replacement with wFCC catalyst. The following main conclusions can be drawn from the experimental results presented in this paper:

- wFCC catalyst incorporation in cement mortars improves the resistance against both to water absorption and to chloride migration compared to the plain cement control mortar;

- the values of both capillary absorption coefficients and chloride migration coefficients decrease linearly with the increase in wFCC catalyst content in the mortars but the reduction is more pronounced for chloride migration coefficient values;

- the wFCC catalyst incorporation in cement mortars leads to a decrease in the resistance to the $\mathrm{CO}_{2}$ inward diffusion which lead both to an increase in the carbonation depth and rate;

- carbonation rate data obey to a power-law relationship with time, $t^{n}$, in which the exponential factor, $n$, lies in the range of 0.40 to 0.60 and increases with the wFCC catalyst content in the mortars;

- increasing the wFCC catalyst content in the mortars mitigates the ASR expansion within the range of 25 to $46 \%$. This behavior is attributed to the high ability of the wFCC catalyst particles to trap the alkali-ions reducing their availability to participate in the reaction with the aggregates.

In brief, this investigation revealed that the incorporation of wFCC catalyst in mortars improve durability parameters in terms of water absorption resistance, chloride migration resistance and ASR expansion. However, under the adopted experimental conditions, this waste presence lead to a decrease in mortars resistance against carbonation As such, deeper studies should be undertaken aiming to optimize the mortars mixture proportions, namely water-to-binder ratio, as well as the curing time period and conditions that minimize or overcome this weakness.

Therefore, beyond the significant environmental and technological benefits of using wFCC catalyst as a poz- 
zolanic material, the present study confirms that this material is also promising with respect to mortars durability.

\section{Acknowledgements}

The authors acknowledge the support of the Portuguese national funding agency for science, research and technology (Fundação para a Ciência e Tecnologia) and the Portuguese oil company (Petróleos de Portugal/PETROGAL S.A.) through project funding PTDC/ECM/113115/2009.

\section{References}

[1] Pacheco Torgal, F. and Jalali, S. (2011) Eco-Efficient Construction and Building Materials. Springer, London. http://dx.doi.org/10.1007/978-0-85729-892-8

[2] Naik, T.R. and Asce, F. (2008) Sustainability of Concrete Construction. Practice Periodical on Structural Design and Construction, 13, 98-103. http://dx.doi.org/10.1061/(ASCE)1084-0680(2008)13:2(98)

[3] Aïtcin, P-C. (2007) Binders for Durable and Sustainable Concrete. Modern Concrete Technology Series No. 16, CRC Press, Bacon Raton.

[4] Naik, T.R. and Moriconi G. (2005) Environmental Friendly Durable Concrete Made with Recycled Materials for Sustainable Concrete Construction. Proceedings of International Symposium on Sustainable Development of Cement, Concrete and Concrete Structures, 5-7 October 2005, Toronto, 485-505.

[5] Massazza, F. (2004) Pozzolana and Pozzolanic Cements. In: Hewlett, P.C., Ed., Lea's Chemistry of Cement and Concrete, 4th Edition, Elsevier Science \& Technology Books, 471-631.

[6] Siddique, R. and Khan, M.I. (2011) Supplementary Cementing Materials. Engineers Materials Series No. 37, Springer, Berlin, Heidelberg. http://dx.doi.org/10.1007/978-3-642-17866-5

[7] Pacewska, B., Bukowska, M., Wilinska, I. and Swat, M. (2002) Modification of the Properties of Concrete by a New Pozzolan-A Waste Catalyst from the Catalytic Process in a Fluidized Bed. Cement and Concrete Research, 32, 145-152.

[8] Wu, J.-H., Wu, W.-L. and Hsu, K.-C. (2003) The Effect of Waste Oil-Cracking Catalyst on the Compressive Strength of Cement Pastes and Mortars. Cement and Concrete Research, 33, 245-253. http://dx.doi.org/10.1016/S0008-8846(02)01006-2

[9] Payá, J., Monzó, J., Borrachero, M.V. and Velázquez, S. (2003) Evaluation of the Pozzolanic Activity of Fluid Catalytic Cracking Catalyst Residue (FC3R). Thermogravimetric Analysis Studies on FC3R-Portland Cement Pastes. Cement and Concrete Research, 33, 603-609. http://dx.doi.org/10.1016/S0008-8846(02)01026-8

[10] Chen, H.-L., Tseng, Y.-S. and Hsu, K.-C. (2004) Spent FCC Catalyst as a Pozzolanic Material for High Performance Mortars. Cement and Concrete Composites, 26, 657-664. http://dx.doi.org/10.1016/S0958-9465(03)00048-9

[11] Antiohos, S.K., Chouliara, E. and Tsimas, S. (2006) Re-Use of Spent Catalyst from Oil-Cracking Refineries as Supplementary Cementing Material. China Particuology, 4, 73-76. http://dx.doi.org/10.1016/S1672-2515(07)60238-3

[12] García de Lomas, M., Sánchez de Rojas, M. and Frías, M. (2007) Pozzolanic Reaction of a Spent Fluid Catalytic Cracking Catalyst in FCC-Cement Mortars. Journal of Thermal Analysis and Calorimetry, 90, 443-447. http://dx.doi.org/10.1007/s10973-006-7921-7

[13] Zornoza, E., Payá, J. and Garcés, P. (2008) Chloride-Induced Corrosion of Steel Embedded in Mortars Containing Fly Ash and Spent Cracking Catalyst. Corrosion Science, 50, 1567-1575. http://dx.doi.org/10.1016/j.corsci.2008.02.001

[14] Cherem da Cunha, A.L., Lemos, M.S., Meth, S., Gonçalves, J.P. and Dweck, J. (2011) A Study of the Particle Size Effect on the Pozzolanic Activity of an Equilibrium Catalyst. Journal of Thermal Analysis and Calorimetry, 106, 805809. http://dx.doi.org/10.1007/s10973-011-1399-7

[15] Costa, C. and Marques, P. (2012) Low-Carbon Cement with Waste Oil-Cracking Catalyst Incorporation. Proceedings of the 2012 IEEE-IAS/PCA 53rd Cement Industry Technical Conference, San Antonio, 14-17 May 2012, 1-9.

[16] Costa, C., Carvalho, P.A. and Marques, P. (2012) Relationship between Microstructure and Mechanical Properties of Binary Blended Cement Mortars Containing Waste Oil-Cracking Catalyst. Proceedings of the International Congress on Durability of Concrete ICDC, Trondheim, 18-21 June 2012, 1-9.

[17] Payá, J., Monzó, J.M, Borrachero, M.V. and Velázquez, S. (2013) Pozzolanic Reaction Rate of Fluid Catalytic Cracking Catalyst Residue (FC3R) in Cement Pastes. Advances in Cement Research, 25, 112-118. http://dx.doi.org/10.1680/adcr.11.00053

[18] Lin, K.-L., Wu, H.-H., Chao, S.-J., Cheng, A. and Hwang, C.-L. (2013) Characteristics of Waste Catalyst Reused as Latent Hydraulic Materials. Environmental Progress \& Sustainable Energy, 32, 94-98.

http://dx.doi.org/10.1002/ep.10616 
[19] Silva, F., Fiuza Junior, R., Silva, J., Brito, C., Andrade, H. and Gonçalves, J. (2014) Consumption of Calcium Hydroxide and Formation of C-S-H in Cement Pastes. Journal of Thermal Analysis and Calorimetry, 116, 1-7. http://dx.doi.org/10.1007/s10973-013-3546-9

[20] Castellanos, N.T., Izquierdo García, S., Agredo, J.T. and Mejía de Gutierrez, R. (2014) Resistance of Blended Concrete Containing an Industrial Petrochemical Residue to Chloride Ion Penetration and Carbonation. Ingeniería e Investigación, 34, 11-16.

[21] European Cracking Catalysts Producers Association (ECCPA) (2006) FCC Equilibrium Catalyst (Including FCC Catalyst Fines) Finds Safe Reuse/Rework Outlets in Europe. http://www.cefic.org/Documents/Other/Ecat outlets Europe 04Jan2006\%20final\%20Dec06.pdf

[22] Pavol, H. (2011) FCC Catalyst-Key Element in Refinery Technology. Proceedings of the 45th International Petroleum Conference, Bratislava, 13 June 2011. http://www.vurup.sk/sites/default/files/downloads/46_ft_hudec-fcc.pdf

[23] Tonetto, G., Atias, J. and Lasa, H. (2004) FCC Catalysts with Different Zeolite Crystallite Sizes: Acidity, Structural Properties and Reactivity. Applied Catalysis A: General, 270, 9-25. http://dx.doi.org/10.1016/j.apcata.2004.03.042

[24] Costa, C., Laginha, I. and Carvalho, P.A. (2013) Microscopy: A Tool for Quantitative Pozzolanic Activity in Blended Cements. Microscopy and Microanalysis, 19, 97-98. http://dx.doi.org/10.1017/S1431927613001104

[25] António, J.L., Silva, P.R. and Costa, C. (2013) Fresh Properties and Compressive Strength of Self Compacting Concrete Containing Waste Fluid Catalytic Cracking Catalyst. In: Roussel, N. and Bessaies-Bey, H., Eds. Proceedings of the 7th RILEM International Conference on Self-Compacting Concrete and 1st RILEM International Conference on Rheology and Processing of Construction Materials, Paris, 1-6 September 2013, 1-8.

[26] Antunes, M. (2014) ECO-Concrete with Addition of a Waste from Oil Refinery. MS Thesis, High Institute of Engineering of Lisbon, Lisbon. (In Portuguese)

[27] Costa, C., Ferreira, C., Ribeiro, M.F. and Fernandes, A. (2014) Alkali-Activated Binders Produced from Petrochemical Fluid Catalytic Cracking Catalyst Waste. International Journal of Research in Engineering and Technology, 3, 114122.

[28] Basheer, L., Kropp, J. and Cleland, D.J. (2001) Assessment of the Durability of Concrete from Its Permeation Properties: A Review. Construction and Building Materials, 15, 93-103. http://dx.doi.org/10.1016/S0950-0618(00)00058-1

[29] Shahidul, I.M. and Sazeda, A. (2013) A Critical Assessment to the Performance of Alkali-Silica Reaction (ASR) in Concrete. Canadian Chemical Transactions, 1, 253-266.

[30] Sisomphon, K. and Franke, L. (2007) Carbonation Rates of Concretes Containing High Volume of Pozzolanic Materials. Cement and Concrete Research, 37, 1647-1653. http://dx.doi.org/10.1016/j.cemconres.2007.08.014

[31] Dias, W.P.S. (2013) Factors Influencing the Service Life of Buildings. Engineer, XXXXVI, 1-7.

[32] Papadakis, V.G. (2000) Effect of Supplementary Cementing Materials on Concrete Resistance against Carbonation and Chloride Ingress. Cement and Concrete Research, 30, 291-299. http://dx.doi.org/10.1016/S0008-8846(99)00249-5

[33] Zornoza, E., Payá, J., Mobzó, J., Borrachero, M.V. and Garcés, P. (2009) The Carbonation of OPC Mortars Partially Substituted with Spent Fluid Catalytic Catalyst (FC3R) and Its Influence on Their Mechanical Properties. Construction and Building Materials, 23, 1323-1328. http://dx.doi.org/10.1016/j.conbuildmat.2008.07.024

[34] Ruthven, D.M. (1984) Principles of Adsorption and Adsorption Processes. John Wiley \& Sons, Hoboken, 467-524.

[35] Ferreira, D.R. and Schulthess, C.P. (2011) The Nanopore Inner Sphere Enhancement Effect on Cation Adsorption: Sodium, Potassium, and Calcium. Soil Science Society of America Journal, 75, 389-396. http://dx.doi.org/10.2136/sssaj2010.0130nps

[36] Karakurt, C. and Topçu, I.B. (2011) Effect of Blended Cements Produced with Natural Zeolite and Industrial ByProducts on Alkali-Silica Reaction and Sulfate Resistance of Concrete. Construction and Building Materials, 25, 17891795. http://dx.doi.org/10.1016/j.conbuildmat.2010.11.087

[37] Shekarchi, M., Bonakdar, A., Bakhshi, M., Mirdamadi, A. and Mobassher, B. (2010) Transport Properties in Metakaolin Blended Concrete. Construction and Building Materials, 24, 2217-2223. http://dx.doi.org/10.1016/j.conbuildmat.2010.04.035

[38] Maas, A., Ideker, J.H. and Juenger, M.C.G. (2007) Alkali Silica Reactivity of Agglomerated Silica Fume. Cement and Concrete Research, 37, 166-174. http://dx.doi.org/10.1016/j.cemconres.2006.10.011 
Scientific Research Publishing (SCIRP) is one of the largest Open Access journal publishers. It is currently publishing more than 200 open access, online, peer-reviewed journals covering a wide range of academic disciplines. SCIRP serves the worldwide academic communities and contributes to the progress and application of science with its publication.

Other selected journals from SCIRP are listed as below. Submit your manuscript to us via either submit@scirp.org or Online Submission Portal.
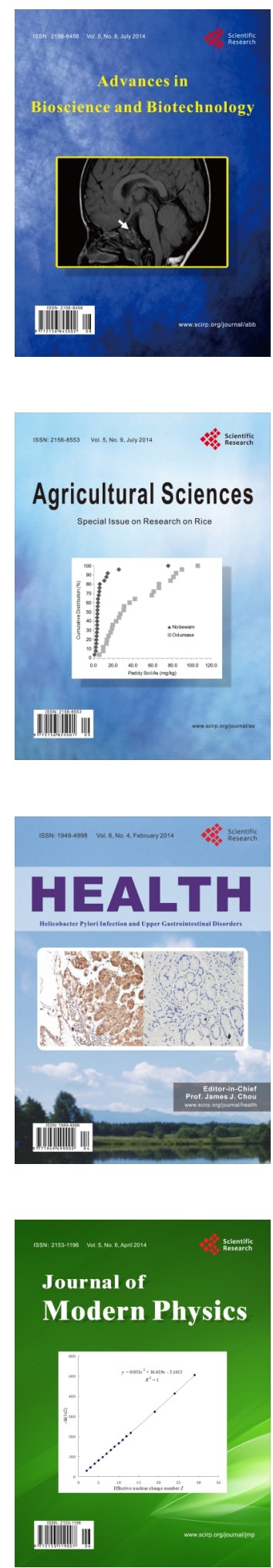
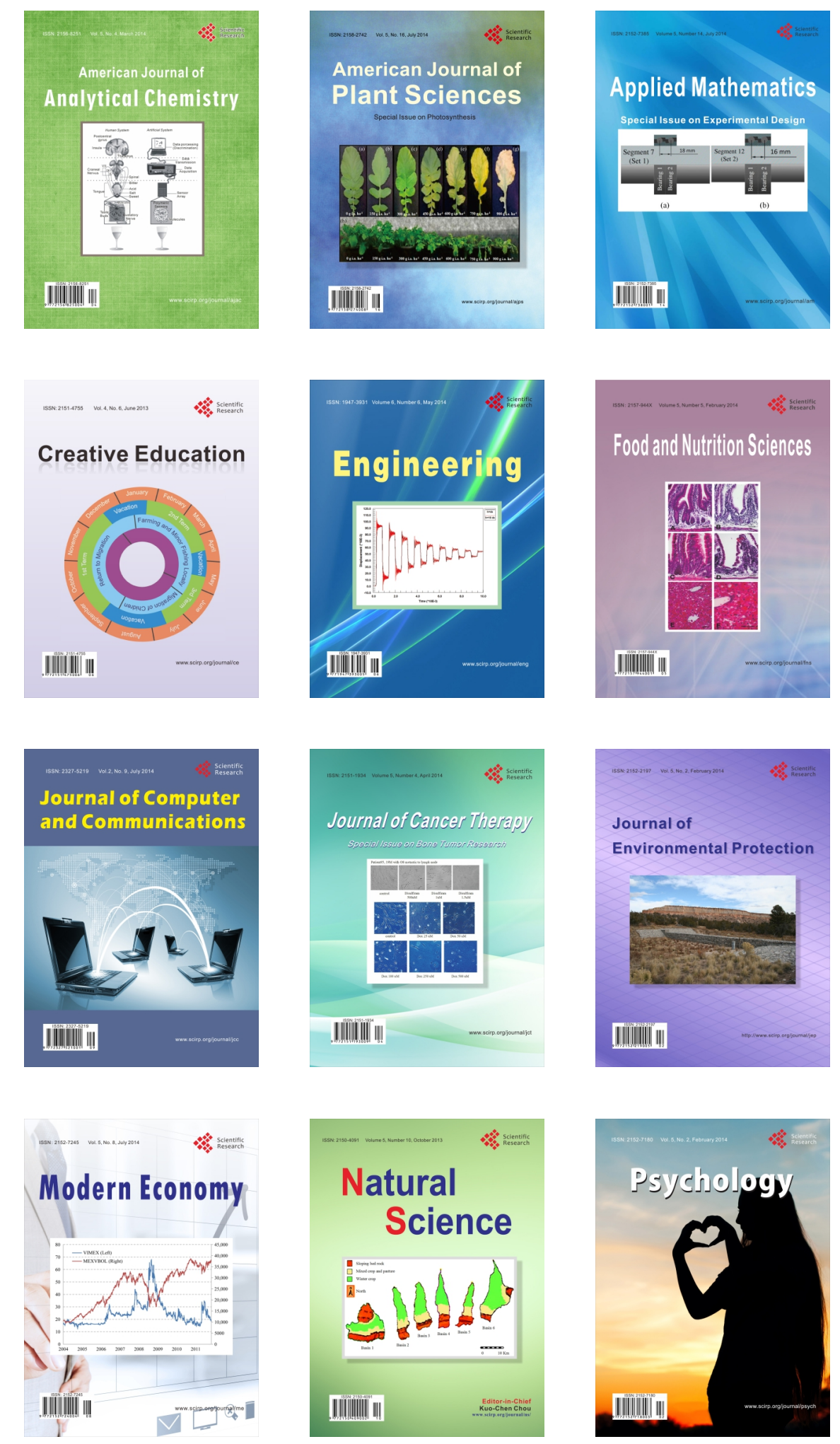